\title{
PORTRAIT OF YOU AS AN ISOLATED CIRCLE
}

\section{Meg Buzzi}

Enough of you is visible, that is, circumference appears and disappears as that form of space tightening, (pursed lips or common eyes) critically rendered.

Here, the net or frame passes over your head, through a hole or plane which misses you entirely.

Here, a Venn diagram sets you, lonely, into an old, blank and silent space.

There is enough visible deposited below the camber like sound, the one provision of your sentences.

Charge of the nameless mathematics, searching the cloud of your unhinged body with a teleologist's comb-

Keep yourself together, claim heat, at least, claim to have produced such movements- 
Grids hover like empty doorframes or glass boxes with no breath. How did this happen to you, space passing over your head? 